treating underlying disease or at affecting mood and an understanding emotional support.

Having said all this, one must still welcome the study by Bungay et al as a carefully executed and well presented account of the verbal aspects of the folkloric expression of the menopause in southern Britain and the pool of "middle-age symptoms" from which they are chosen.

JOEL WILBUSH
Edmonton,
Alberta T5M OY5,
Canada

1 Neugarten BL, Kraines RJ. Psychosom Med $1965 ; 27$ :
266-73.
2 Donovan JC. Am 7 Obst Gynec $1951 ; 62: 1281-91$.
3 Wilbush J. Maturitas (in press).
' Cullen W. Synopsis nosologiae methodicae. Edinburgh:
1769.
${ }^{5}$ Wilbush J. DPhil thesis. Oxford:1980.

\section{Retroperitoneal fibrosis associated with atenolol}

SIR,-There are many points raised in the two letters concerning retroperitoneal fibrosis and beta-blockers (26 July, p 311). For conciseness I will reply only to the main points raised, largely by using their figures and diagram. Quotations are from the letters.

I consider first the letter of $\mathrm{Dr}$ Winifred $\mathrm{M}$ Castle and others:

(1) "We feel that beta-blockers are no more likely than other antihypertensive agents to be associated with retroperitoneal fibrosis." Reports of retroperitoneal fibrosis to the Committee on Safety of Medicines (August 1980) total 30: eight with methysergide, 14 with beta-blockers, and eight with other drugs. In this last group of eight a total of 20 drugs are listed, 19 of which appear only once. Thus beta-blockers as a group predominate.

(2) They consider that retroperitoneal fibrosis occurs merely coincidentally with beta-blocker therapy and consider it "hardly surprising." On their figures, three cases are reported with 3000000 patient years of therapy for propranolol and four cases with 600000 patient years of practolol and atenolol therapy, two compounds with some structural similarity. This distribution would occur by chance less than one in 50 times $(p<0.018$, Fisher's test). Thus some beta-blockers may be more likely than others to be associated with retroperitoneal fibrosis. (It should, however, be noted that pindolol was also taken in one of the two practolol cases.)

(3) While, as Dr Castle and her colleagues note, a number of patients have been transferred from practolol to atenolol with resolution of their "fibrosing oculomucocutaneous syndrome" they omit to say that the 14 patients reported by Zacharias $^{1}$ were described as having ocular and cutaneous lesions and not sclerosing peritonitis.

The letter of Dr F L Rose and Professor F Bergel contains three main points:

(1) "The mass of a drug substituent group has no accurately definable relationship to its biological activity." A drug-receptor interaction, in som respects, may be likened to a lock-and-key relationship, just as with an enzyme-substrate interaction. While not all Yale keys open all Yale locks I would suggest that the choice of a key of appropriate design and size increases one's chances of obtaining the desired (or, in the case of a drug side effect, undesired) result. Atenolol, practolol, and oxprenolol all provide keys of the same size.

(2) "The strong carbonyl $(-\mathrm{C}=\mathrm{O})$ dipoles of practolol and atenolol face different ways.

With regard to atenolol, there is rotation about the two single bonds between carbonyl carbon and the point of attachment of the side chain to the ring. Rotation about these bonds causes the carbonyl dipole of atenolol also to face to the right, most easily seen with molecular models. The carbonyl oxygen sweeps out a volume in space as the bond rotates-hence the usefulness of the "nebulous

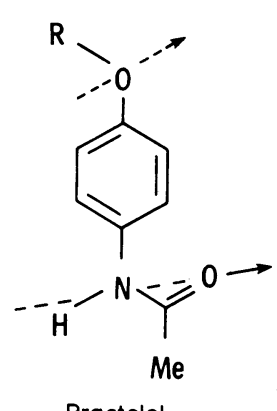

Practolol

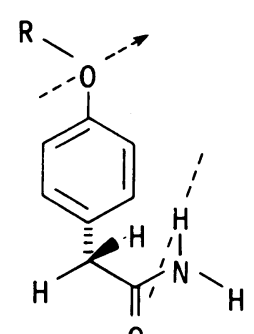

0

Atenolol concept of associated electron clouds." There is little rotation about the carbonyl-nitrogen bond in either molecule. These bonds have partial doublebond character, similar indeed to the amide linkage in proteins. Viewing practolol from the reverse face of the benzene ring causes the dipole to be directed to the left, not the right. Unfortunately, calculations of most stable dipole directions in solution do not give information about dipole direction when bound to a receptor.

(3) The statement that the partition coefficient is "the important $\pi$ factor determining biological activity in Hansch functions" is misleading. Many other factors are involved. ${ }^{2}$ Thus oil-water partition coefficients for salicylamide and phenobarbitone are both 5.9 , for barbitone 1.4 , and for amidopyrine $1 \cdot 3 .^{3}$ The reader may judge how well biological activity and partition coefficient correlate for these substances. Similarly, atenolol and oxprenolol have different partition coefficients but the common biological activity of beta-blockade. Partition coefficients in fact give more information about pharmacokinetic handling than biological activity.

Overall I do not share the confidence of Dr Castle and her colleagues that "the evidence to date is reassuring." Readers may judge for themselves whether there is a small cloud of suspicion overhanging beta-blockers in general, and perhaps some in particular, with respect to their association with retroperitoneal fibrosis.

St James's Hospital,

D W Bullimore

Zacharias FJ. Br Med f 1976; i : 1213. vol 11-1. London: Academic Press. 1971, chemistry vol 11-1. London: Academic Press. 1971, 271-337. cology. 2nd ed. Oxford: Blackwell Scientific Pubcology. 2nd ed. Oxf
lications, $1980: 40-3$.

\section{Physical training and coronary risk factors}

SIR,-Dr P E Moffitt (9 August, p 453) surely is justified in emphasising the difference be tween risk factors, as studied by Dr Antony W Sedgwick and others (5 July, p 7), and actua occurrence of coronary disease, if only because the media are so liable to get it wrong-as indeed happened in this instance. Moreover, it is doubtful whether there is particular point in further search for the mechanisms or pathways of a possible protective effect of exercise agains coronary heart disease in the classical risk factors. ${ }^{1}$ Interest has shifted to the training process itself ${ }^{2}$-for example, to thrombosis and lysis $^{34}$ and to the improvement in lipoprotein patterns with the rise of high-density lipoproteins. $^{5}$

I hasten to add, however, that the middleaged civil servants in our own study ${ }^{6}$ did not engage in "violent" exercise. No marathons all-in wrestling, judo, or karate, no rugger, not even squash. . . . The definition of vigorous exercise in leisure-time is that likely to incur peaks of energy expenditure of $31.5 \mathrm{~kJ}(7.5$ kcal) per minute. The forms commonly taken, presumably enjoyed, and encouragingly associated with a low incidence of coronaries in eight and a half years of follow-up (recently completed) are swimming, tennis, brisk walking, running (jogging), hill climbing, keep-fit exercises, and the like.

\section{London School of Hygiene and}

J N MORRIS Tropical Medicine,
London WC1E 7HT \section{${ }^{1}$ Paffenbarger RS. In: Amsterdam EA, Wilmore JH and disease. New York: Yorke Medical Books, 1977:35-49. \\ 2 Gyntelberg F, Danish Med Bull 1974 ;21 :49-56. \\ Morris JN. Uses of epidemiology. 3rd edn. London: Churchill Livingstone, 1975. \\ 1980;302:987-91. \\ 5 Wood PD, Haskell WL. Lipids 1979;14:417-27.
${ }^{6}$ Morris JN, Chave SPW, Adam C, Sirey C, Eps \\ Sheehan D. \\ . Lancet 1973;i:333-9.}

\section{Hyperlipidaemia advances and retreats}

SIR,-As a general practitioner at present engaged in a research project to correct major risk factors for ischaemic heart disease in a random sample of one-third of our patients between the ages of 20 and 60 , I find that the leading article on hyperlipidaemia (2 August, p 340) presents an extremely poor representation of the correct situation regarding the treatment of hyperlipidaemia.

While the subject is clearly controversial, it needs to be stated quite emphatically that even the authors of the report on the WHO clofibrate trial were extremely puzzled by a number of anomalies in the trial. To state that the overall increased mortality outweighed the benefit for the person studied would appear to amount to a failure to recognise the basic problem experienced by any attempt to perform a double-blind randomised trial of a drug in a complicated multifactorial disease. When one looks carefully and critically at the failure of clofibrate to reduce the overall death rate in the treated compared with the non-treated hyperlipidaemic group, it will be noted that the excess mortality in the treated group was in fact in the disease category of malignancy. It will be further noted that the malignancies with the most significant difference between the two groups were, firstly, carcinoma of the bronchus and, secondly, the carcinomas of the oesophagus and stomach. If we add these two groups of malignancies together in the clofibrate group of patients, 26 patients died of these predominantly smoking-related carcinomas, whereas in the non-treated group only 15 patients died from these carcinomas.

The only conclusion which one could reach in the circumstances is that the investigators had, not surprisingly, found extreme difficulty in actually matching the smoking levels of the members of the two hyperlipidaemic groups. Since fatal myocardial infarction is relatively more common when it presents in smokers than in non-smokers, ${ }^{2}$ it would seem that this discrepancy in the smoking levels in the two groups may also be the basic underlying reason why clofibrate reduced the non-fatal myocardial infarction by $30 \%$ but failed to influence the mortality rate of the two groups from myocardial infarction. In the circumstances it would be unwise to write off the use of clofibrate in hyperlipidaemia, as appears to have been the case, on the basis of the WHO trial, as quite clearly, attempting to assess a drug of this sort in a multifactorial disease throws extreme doubt on the validity of the trial one way or the other.

The end of the leading article on hyperlipidaemia was so vague in its recommendations for the physician that as an experienced worker in this field one was left wondering whether the article was based on actual experience of the problem of the primary prevention of arterial disease by 